\title{
Regulatory Efficacy of Spirulina platensis Protease Hydrolyzate on Lipid Metabolism and Gut Microbiota in High-Fat Diet-Fed Rats
}

\author{
Pengpeng Hua ${ }^{1} \mathbb{D}$, Zhiying $\mathrm{Yu}^{2}$, Yu Xiong ${ }^{2}$, Bin Liu ${ }^{1,2, *}$ and Lina Zhao ${ }^{2, *}$ \\ 1 College of Food Sciences, Fujian Agriculture and Forestry University, Fuzhou 350002, China; \\ huapengpeng_flower@163.com \\ 2 National Engineering Research Center of JUNCAO Technology, Fujian Agriculture and Forestry University, \\ Fuzhou 350002, China; 18838018055@163.com (Z.Y.); aindxiong@163.com (Y.X.) \\ * Correspondence: liubin618@hotmail.com (B.L.); zln20002000@163.com (L.Z.)
}

Received: 29 October 2018; Accepted: 11 December 2018; Published: 13 December 2018

\begin{abstract}
Lipid metabolism disorder (LMD) is a public health issue. Spirulina platensis is a widely used natural weight-reducing agent and Spirulina platensis is a kind of protein source. In the present study, we aimed to evaluate the effect of Spirulina platensis protease hydrolyzate (SPPH) on the lipid metabolism and gut microbiota in high-fat diet (HFD)-fed rats. Our study showed that SPPH decreased the levels of triglyceride (TG), total cholesterol (TC), low-density-lipoprotein cholesterol (LDL-c), alanine transaminase (ALT), and aspartate transaminase (AST), but increased the level of high-density-lipoprotein cholesterol (HDL-c) in serum and liver. Moreover, SPPH had a hypolipidemic effect as indicated by the down-regulation of sterol regulatory element-binding transcription factor-1c (SREBP-1c), acetyl CoA carboxylase (ACC), SREBP-1c, and peroxisome proliferator-activated receptor- $\gamma(\operatorname{PPAR} \gamma)$ and the up-regulation of adenosine 5 '-monophosphate (AMP)-activated protein kinase (AMPK) and peroxisome proliferator-activated receptor $\alpha$ (PPAR $\alpha$ ) at the mRNA level in liver. SPPH treatment enriched the abundance of beneficial bacteria. In conclusion, our study showed that SPPH might be produce glucose metabolic benefits in rats with diet-induced LMD. The mechanisms underlying the beneficial effects of SPPH on the metabolism remain to be further investigated. Collectively, the above-mentioned findings illustrate that Spirulina platensis peptides have the potential to ameliorate lipid metabolic disorders, and our data provides evidence that SPPH might be used as an adjuvant therapy and functional food in obese and diabetic individuals.
\end{abstract}

Keywords: Spirulina platensis protease hydrolyzate; peptides; lipid metabolism disorder; gene expression; gut microbiota

\section{Introduction}

The improvement in living standards worldwide and the increasing intake of poor quality food, at least from the nutritional point of view, have resulted in an increasing frequency of lipid metabolism disorder (LMD) [1]. LMD is a risk factor for obesity, hyperlipidemia, hyperglycemia, hypertension, fatty liver, cardiopathy, clinical syndrome, and other metabolic syndromes. It is also one of the most threatening public health problems in the world [2]. According to the statistics of the World Health Organization, the above-mentioned diseases are responsible for more than 18 million deaths annually. LMD is characterized by high levels of triglyceride (TG), total cholesterol (TC), and low-density-lipoprotein cholesterol (LDL-c), coupled with low levels of high-density-lipoprotein cholesterol (HDL-c) [3]. Dysregulation of lipid metabolism in the liver induces abnormal accumulation of lipids and the subsequent formation of lipid droplets, known as hepatosteatosis. Adipose tissue, 
an endocrine organ that secretes a number of adipokines known to mediate lipid metabolism, inflammation, and insulin sensitivity, is also critical in metabolic control [4]. Due to the medical importance of LMD, considerable research has been devoted to develop appropriate treatments. Although several drugs have been approved by the US Food and Drug Administration to treat obesity, their efficacy is often low and side effects are common [5,6]. Therefore, it is urgently necessary to develop a well-tolerated treatment with minimal side effects for obesity.

Recently, hydrolysate from several plants has been reported to have LMD-preventing effects. These plants include lucid ganoderma $[7,8]$. Several active anti-obesity ingredients present in plants have also been identified, such as Kefir peptides from lucid ganoderma and peptide 2 from Grifola frondosa. Many soy peptides have been identified to lower cholesterol and triglycerides, which can suppress fat synthesis and storage in different experimental systems [9]. These plant extracts and natural compounds have considerable potential to be further developed into effective therapies for LMD [10].

Spirulina platensis, belonging to the family Oscillatoriaceae [11], grows naturally in alkaline lakes [12], and it is a special formula consisting of active constituents, including minerals, vitamins and proteins, beta-carotene, tocopherols, and phenolic acids, exhibiting high anti-inflammatory and antioxidant activities [13,14], especially essential amino acids [15,16]. Therefore, it is used as a food supplement for human and feed additives for many animal species as well as birds and fishes. Moreover, Spirulina platensis and its highly active ingredient (C-phycocyanin) exhibits anti-inflammatory, immunomodulatory, hepatoprotective, nephroprotective, neuroprotective, antidiabetic, antigenotoxic, anti-hypertensive, and anticancer activities [17-20]. More recently, Spirulina platensis has received increasing attention due to their potential biological activities, including ACE-inhibitory, antioxidant, and LMD-preventing properties [21]. However, the effects of Spirulina platensis protease hydrolyzate (SPPH) on dysregulated lipid metabolism in liver and adipose tissue of diet-induced obesity have not yet been fully elucidated.

At the molecular level, the major transcription factors, such as PPAR $\gamma$, SREBP-1c, and AMPK, have been implicated in the regulation of obesity. Previous studies have shown that the down-regulation of lipogenic proteins and up-regulation of lipolytic proteins mitigates obesity and dyslipidemia in a high calorie diet-induced rodent model [22,23]. PPAR family plays an essential role in lipid metabolism and is mainly expressed in adipose tissue, liver, and skeletal muscle, mediating obesity / anti-obesity signaling events. PPAR $\alpha$ regulates the metabolism of lipids, carbohydrates, and amino acids, and it can be activated by ligands [24]. AMPK plays a significant role in lipogenesis and fatty acid oxidation through inactivation of ACC and carnitine palmitolytransferase-1 [25]. SREBP-1C is an important transcriptional factor involved in regulation of key enzymes of lipogenesis, including ACC and FAS. Targeting lipid metabolism has been considered as a potential and alternative strategy to combat obesity [26]. Several studies have shown that gut microbiota plays an important role in the effect of hyperlipidemia. The disturbance of compositions of gut microbiota (the ratio of Firmicutes to Bacteroidetes and endotoxin levels) can affect the gut barrier function and hepatic cholesterol metabolism by several pathways [27-29]. Microbial species are associated with changes in blood lipids. The abundance of particular bacterial genera is negatively correlated with the body mass index and TG, but positively correlated with the HDL-c level. It is widely accepted that drugs can make changes in the gut microbiota, leading to an impact on the body's state.

In the present study, we investigated whether SPPH has an effect on diet-induced obesity. We also measured body weight, serum index, liver index, the expressions of genes involved in adipogenesis, and the compositions of gut microbiota. 


\section{Results}

\subsection{Characterization of Potent Major Compounds}

The peptide sequences of SPPH were identified (Table S1). Our study showed that 217 peptide sequences were found from SPPH. Peaks were observed at different retention times ranging from $1.96 \mathrm{~min}$ to $9.93 \mathrm{~min}$ [30]. Representative chromatograms and MS/MS spectra of high and low abundance peptides are shown (Figures S1-S6).

\subsection{Effect of SPPH on Body Weight and Serum Lipids of HFD-fed Rats}

Table 1 shows the changes in the body weight of the rats during the 8-week experimental period. The average initial body weight was $223.52 \pm 6.15 \mathrm{~g}, 224.28 \pm 6.58 \mathrm{~g}$, and $227.08 \pm 9.84 \mathrm{~g}$ for NFD (normal fat diet), HFD (high-fat diet), and SPPH (Spirulina platensis protease hydrolyzate) groups, respectively. After a 4-week experimental period, the body weight of the HFD group was significantly increased compared with the NFD group (Table 1). Moreover, there was a statistically significant difference between the SPPH and HFD groups $(p<0.01)$. After 8 weeks, the average final body weight was $374.58 \pm 16.20 \mathrm{~g}, 412.05 \pm 19.21 \mathrm{~g}$, and $354.09 \pm 13.11 \mathrm{~g}$ for the NFD, HFD, and SPPH groups, respectively. The average body weight of the NFD, HFD, and SPPH groups was increased by $163.14 \pm$ $14.82 \mathrm{~g}, 215.36 \pm 23.70 \mathrm{~g}$, and $169.83 \pm 42.68 \mathrm{~g}$, respectively. SPPH $(150 \mathrm{mg} / \mathrm{kg})$ significantly $(p<0.01)$ reduced the body weight after 8 weeks of oral administration compared with the HFD group, while there was no significant difference between the SPPH group and NFD group.

Table 1. Changes in the body weight of rats in the different groups during the experimental period.

\begin{tabular}{cccc}
\hline \multirow{2}{*}{ Time } & \multicolumn{3}{c}{ Weight $(\mathbf{g})$} \\
\cline { 2 - 4 } & NFD & HFD & SPPH \\
\hline 0 Weeks & $223.52 \pm 6.15$ & $224.28 \pm 6.58$ & $227.08 \pm 9.84$ \\
4 Weeks & $382.69 \pm 31.65^{*}$ & $418.53 \pm 18.48^{\#}$ & $363.02 \pm 42.65^{* *}$ \\
8 Weeks & $374.58 \pm 16.20^{* *}$ & $412.05 \pm 19.21^{\# \#}$ & $354.09 \pm 13.11^{* *}$ \\
Weight gain & $163.14 \pm 14.82^{* *}$ & $215.36 \pm 23.70^{\# \#}$ & $169.83 \pm 42.68^{* *}$ \\
\hline
\end{tabular}

Note: NFD, normal fat diet; HFD, high-fat diet; SPPH, Spirulina platensis protease hydrolyzate. NFD group, rats fed with NFD and gavaged with $150 \mathrm{mg} /(\mathrm{kg} \cdot$ day) normal saline. HFD group, rats fed with HFD and gavaged with $150 \mathrm{mg} /(\mathrm{kg} \cdot$ day) normal saline. SPPH group, rats fed with HFD and gavaged with $150 \mathrm{mg} /(\mathrm{kg} \cdot$ day) Spirulina platensis protease hydrolyzate. Data are expressed as mean $\pm \mathrm{SD}(n=8) .{ }^{\#} p<0.05,{ }^{\# \#} p<0.01$ vs. the NFD group; * $p<0.05$, $* * p<0.01$ vs. the HFD group.

At week 0, there was no significant difference in blood lipid levels among the groups. After 4 weeks, the levels of serum TC, TG, and LDL-c were significantly decreased in the SPPH group compared with the HFD group $(p<0.01$ ) (Figure $1 \mathrm{~A}, \mathrm{~B}, \mathrm{D})$. The HDL-c level in the SPPH group was significantly increased compared with the HFD group $(p<0.01)$ (Figure 1C). After 8 weeks, similar findings were observed, showing that the levels of serum TC, TG, and LDL-c were significantly decreased in the SPPH compared with the HFD group $(p<0.01)$ (Figure 1A,B,D). However, the HDL-c level in the SPPH group was significantly higher compared with the HFD group after 8 weeks of SPPH treatment $(p<0.01$ ) (Figure $1 C$ ). The results showed that the SPPH treatment at a dose of $150 \mathrm{mg} / \mathrm{kg}$ significantly affected the serum lipid profile.

\subsection{Effect of SPPH on Liver Function and Hepatic Steatosis}

To examine the effect of SPPH on biochemical changes, we determined the levels of TG, TC, HDL-c, LDL-c, AST, and ALT in the liver. HFD significantly increased the levels of hepatic TG, TC, LDL-c, AST, and ALT. After 4 weeks, the SPPH treatment group showed markedly reduced levels of TG, TC, LDL-C, AST, and ALT in the liver (Figure 2A,B,D-F). In addition, after 8 weeks, the hepatic HDL-c level in the SPPH group was decreased $(p<0.01)$ compared with the NFD group, while it was increased by approximately 50\% compared with the HFD group (Figure 2C). These results could be 
attributed to the ability of SPPH to effectively suppress accumulation of hepatic TG, TC, and LDL-c in HFD-fed rats. Moreover, the levels of AST and ALT in the HFD group were significantly increased compared with the NFD group, indicating that the rat model of liver dysfunction was successfully established. However, SPPH treatment significantly reduced these two parameters $(p<0.01)$, indicating that SPPH could effectively improve liver function.

A

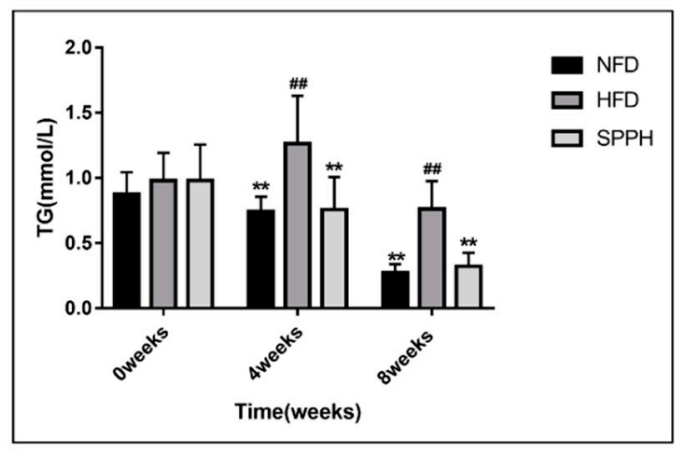

C

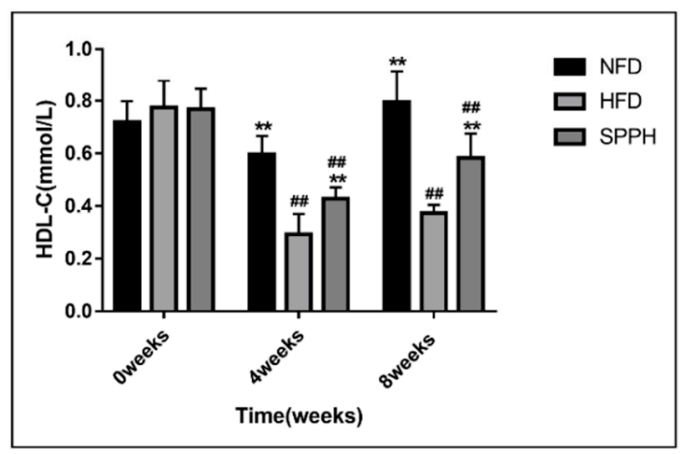

B

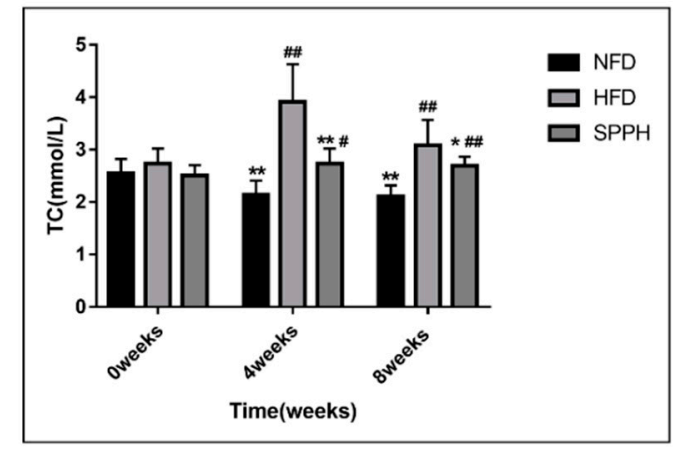

D

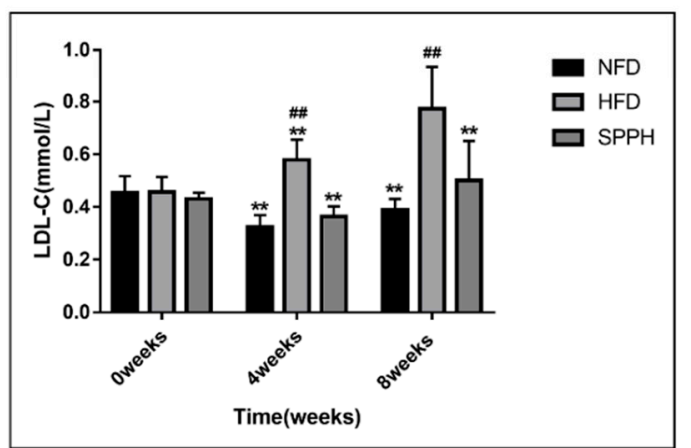

Figure 1. Serum lipid levels of rats in each group during the experimental period. TG (A), TC (B), HDL-c (C), LDL-c (D). Note: NFD, normal fat diet group; HFD, high-fat diet group; SPPH, HFD-fed rats treated with SPPH; NFD group, rats fed with NFD and gavaged with $150 \mathrm{mg} /(\mathrm{kg}$. day) normal saline. HFD group, rats fed with HFD and gavaged with $150 \mathrm{mg} /(\mathrm{kg} \cdot$ day) normal saline. SPPH group, rats fed with HFD and gavaged with $150 \mathrm{mg} /\left(\mathrm{kg} \cdot\right.$ day) Spirulina platensis protease hydrolyzate. ${ }^{\#} p<$ $0.05,{ }^{\#} p<0.01$ vs. the NFD group; ${ }^{*} p<0.05,{ }^{* *} p<0.01$ vs. the HFD group.

H\&E staining showed the effect of SPPH on HFD-induced lipid accumulation in the liver (Figure 3). The liver color of the NFD group was red with a smooth surface, and the liver volume was moderate, accompanied with normal tissue elasticity. Rats in the HFD group had a white and pink liver, as well as a tense capsule with swelling tissue. Compared with the HFD group, the liver in the SPPH group had a rosy color in varying degrees and a greater tissue elasticity. The histopathological examination of the NFD group showed normal cell architecture, the liver cells had polygonal edges with clear cell borders, and the nucleus was round and clear, which was located in the centre of the cell with abundant cytoplasm. However, the HFD control group showed significant morphological changes with greater hepatic lipid accumulation and fatty degeneration, and some cell nuclei apparently exhibited a typical fatty degeneration. Most of the cells in the SPPH group were restored to the normal levels, liver cell cords were arranged normally, and the overall cell degeneration was significantly improved. The results showed that SPPH treatment had a better preventive effect. 
A

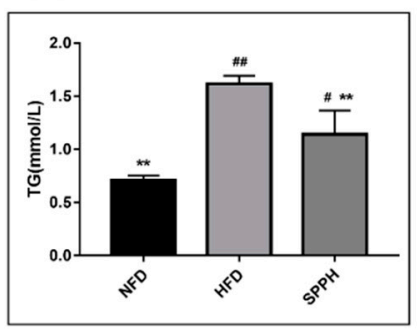

D

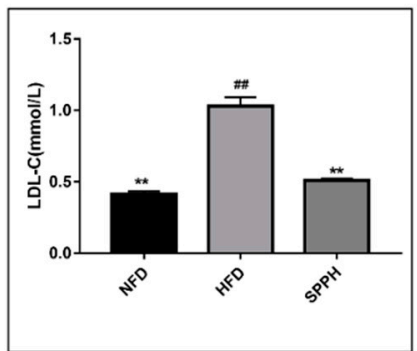

B

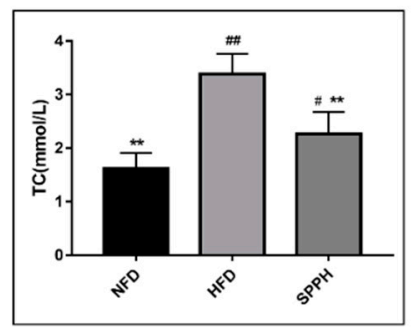

E

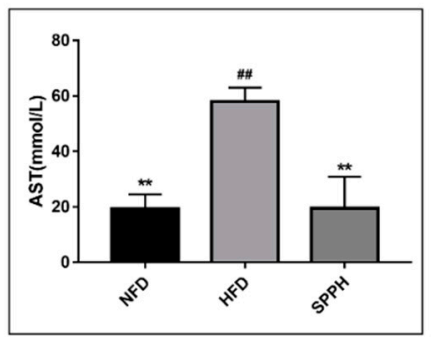

C

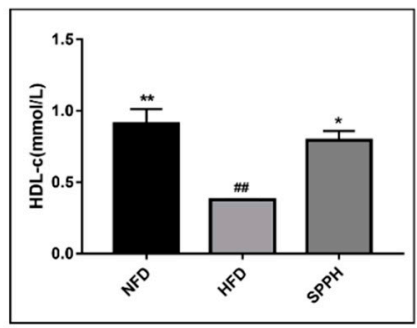

$\mathbf{F}$

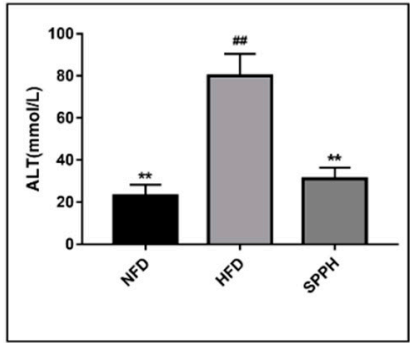

Figure 2. Hepatic lipid levels of rats in each group during the experimental period. TG (A), TC (B), HDL-c (C), LDL-c (D), AST (E), ALT (F). Note: TG, triglyceride; TC, total cholesterol; HDL-c, high-density-lipoprotein cholesterol; LDL-c, low-density-lipoprotein cholesterol. Data are expressed as mean $\pm \mathrm{SD}(\mathrm{n}=8)$. Data are expressed as mean $\pm \mathrm{SD}(\mathrm{n}=8) .{ }^{\#} p<0.05$, ${ }^{\#} p<0.01$ vs. the NFD group; ${ }^{*} p<0.05,{ }^{* *} p<0.01$ vs. the HFD group.
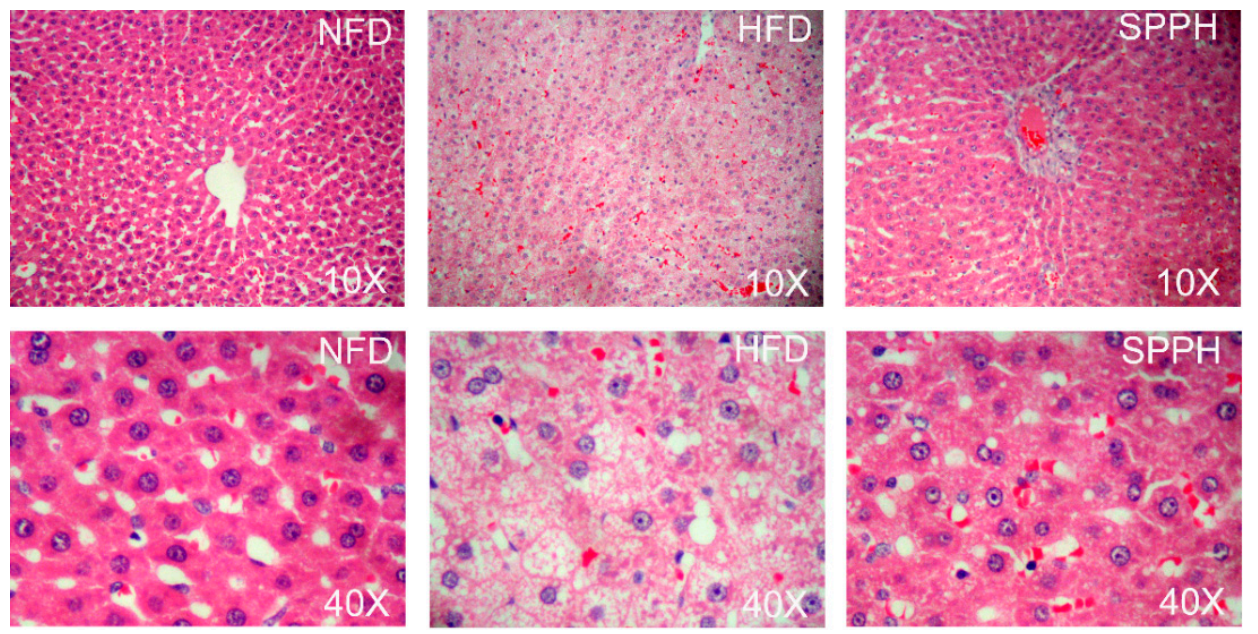

Figure 3. Histopathological analysis of rat hepatic tissues in different groups at $40 \times$ magnification.

2.4. Effect of SPPH on the Expressions of Genes Involved in Lipid and Glucose Metabolism at the mRNA Level

To reveal the molecular mechanism underlying the effects of SPPH treatment, we analyzed the expressions of genes involved in lipid homeostasis in the liver (Figure 4). We assessed hepatic levels of lipogenesis-related genes (SREBP-1c and PPAR $\gamma$ ), as well as fatty acid metabolism-related genes (PPAR $\alpha$ and ACC) in HFD-fed rats. Our data showed that the expression of SREBP-1c was significantly decreased in the SPPH group compared with the HFD group. Of these genes, SREBP-1c and PPAR $\gamma$ were the most significantly decreased ones in the SPPH group $(p<0.01)$ compared with the HFD group. The expressions of PPAR $\alpha$ and ACC, the genes involved in fatty acid $\beta$-oxidation, were significantly decreased in the SPPH group compared with the HFD group $(p<0.01)$, which was similar to that 
observed in NFD-fed rats. Taken together, these results demonstrated that SPPH inhibited fatty acid synthesis and activated fatty acid $\beta$-oxidation in the livers of HFD-fed rats.

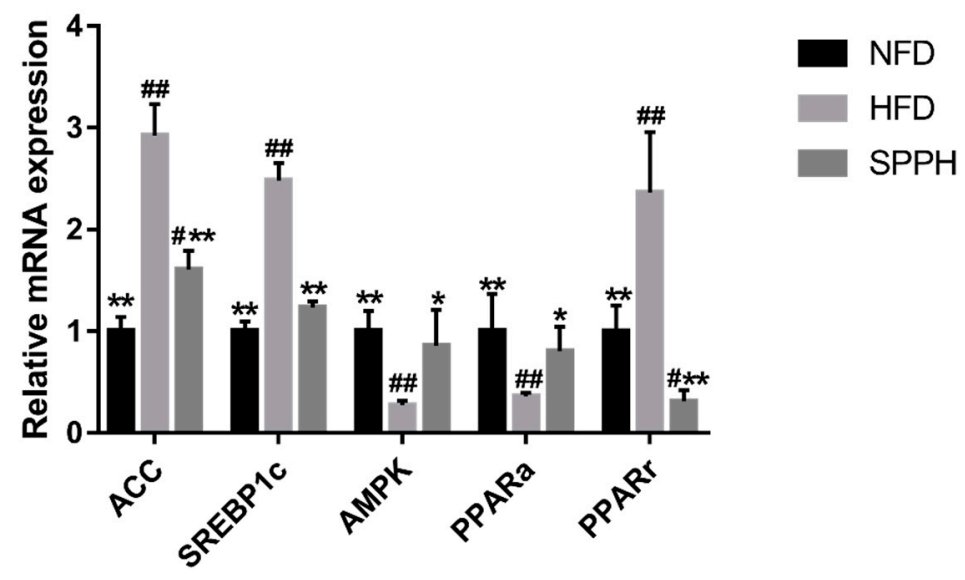

Figure 4. The mRNA and protein expressions levels of genes involved in lipid and glucose metabolism as determined using real-time PCR. Note: The differences were assessed by ANOVA and denoted as follows: ${ }^{\#} p<0.05,{ }^{\# \#} p<0.01$ vs. the NFD group; ${ }^{*} p<0.05,{ }^{* *} p<0.01$ vs. the HFD group.

\subsection{SPPH Modulates Gut Microbiota of HFD-Fed Rats}

To investigate whether the gut microbiota profile was altered by SPPH treatment, we assessed the dominant microbiota population in the NFD, HFD, and SPPH groups (Figure 5). As expected, at the genus level, the alteration of gut microbiota composition by HFD feeding was significant $(p<0.0001)$. The gut microbiota population of the SPPH group was also significantly different from the HFD group $(p<0.05)$. In this study, Lachnospiraceae, Bacteroides, Lactobacillus, Alistipes, and Ruminococcaceae were dominant genera presented in different groups. Through 8 weeks of SPPH treatment, the relative abundances of Porphyromonadaceae, Lachnospiraceae, Prevotella, Ruminococcaceae, Bacteroides, Blautia, Desulfovibrionaceae, Alloprevotella, and Porphyromonadaceae were significantly changed, and Ruminococcus was the most prominently increased one after SPPH treatment at the genus level. Moreover, the abundances of Allobaculum, Firmicutes, Clostridium_XlVa, and Lachnospiracea were decreased in the SPPH group compared with the HFD group. In addition, the lower B/F ratio in the HFD group was increased by SPPH treatment. These results suggested that HFD feeding could dysregulate gut microbiota distribution, while SPPH treatment could partially restore the microbiota distribution to the level of the NFD group.

\subsection{Correlations of Biochemical Data and Key Phylotypes of Caecal Microbiota}

To explore the interactive features between the lipid metabolism-associated parameters and gut microbiota during the HFD-induced obesity development, correlation analysis was performed to examine the possible connection between the abundance of gut bacteria and host metabolic parameters (Figure 6). The microbes (such as Turicibacter, Romboutsia, Phascolarctobacterium, Erysipelotrichaceae, Firmicutes, and Clostridium XVIII) that were significantly enriched in the HFD group were positively correlated with the levels of serum TG, TC, and LDL-c, but negatively correlated with the serum HDL-c level. 


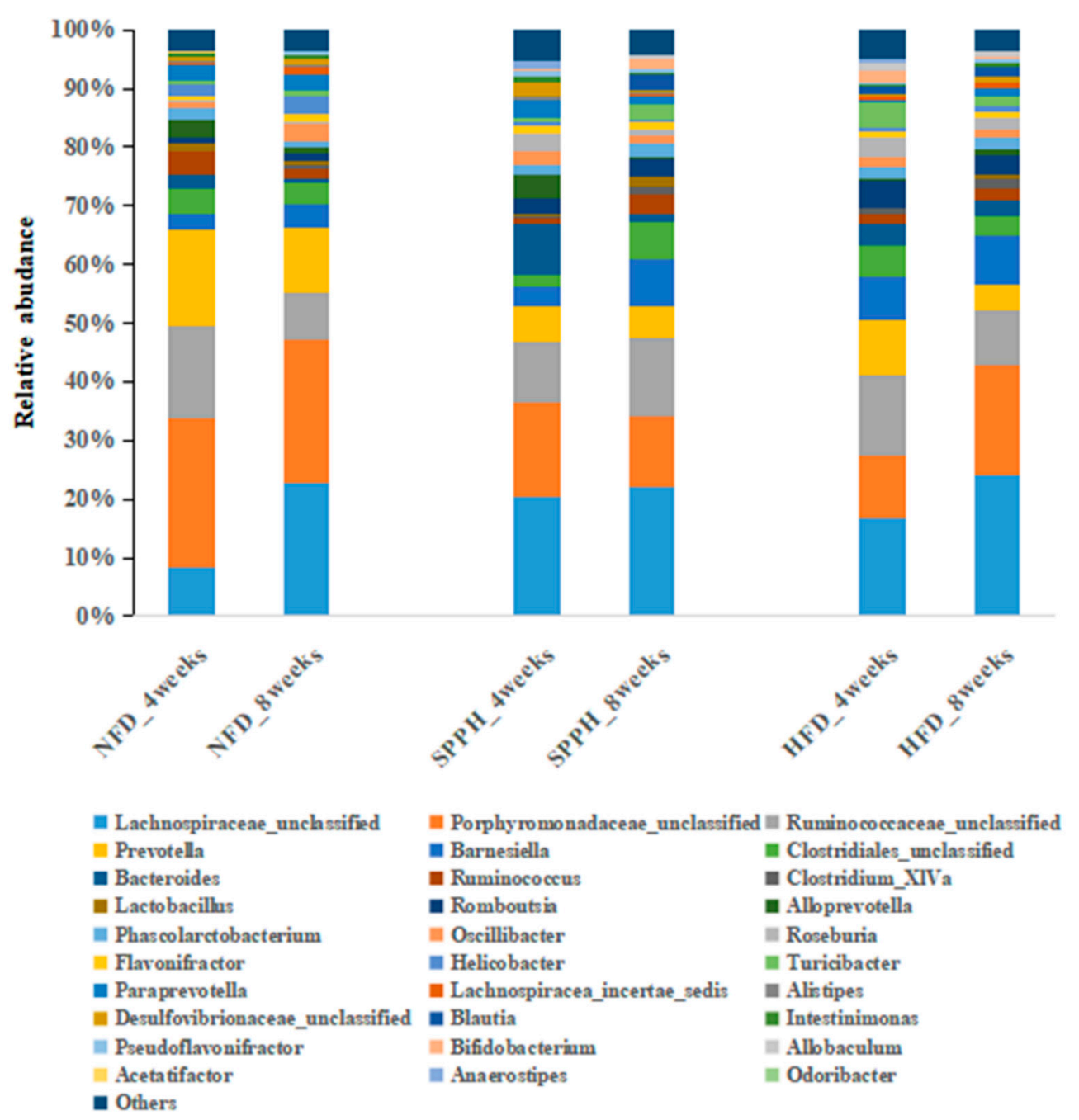

Figure 5. Changes in the bacterial composition of rat intestinal contents according to different genera. Composition of gut microbiota at the genus level.

The relative abundances of Porphyromonadaceae and Desuifovibrionaceae were positively correlated with the serum HDL-c level, while Turicibacter was negatively correlated with the serum HDL-c level. The relative abundances of Coprococcus, Erysipelotrichaceae, Blautia, Allobaculum, Bifidobacterium, Romboutsia, and Phascolarctobacterium were positively correlated with the serum LDL-C level, and the relative abundances of Barnesiella, Oscillibacter, and Paraprevotella were significantly negatively correlated with the serum LDL-c level. Meanwhile, the serum TC level was positively correlated with the relative abundances of Olsenella, Bifidobacterium, Romboutsia, and Phascolarctobacterium, but negatively correlated with Barnesiella, Oscillibacter, and Paraprevotella. Interestingly, body weight was positively correlated with Olsenella, Allobaculum, Bifidobacterium, and Phascolarcto, but negatively correlated with Oscillibacter and Paraprevotella. Moreover, the serum TG level was positively correlated with Romboutsia and Phascolarcto, but negatively correlated with Barnesiella and Paraprevotella, suggesting that these bacteria constituted an important factor in the beneficial effect of SPPH. 


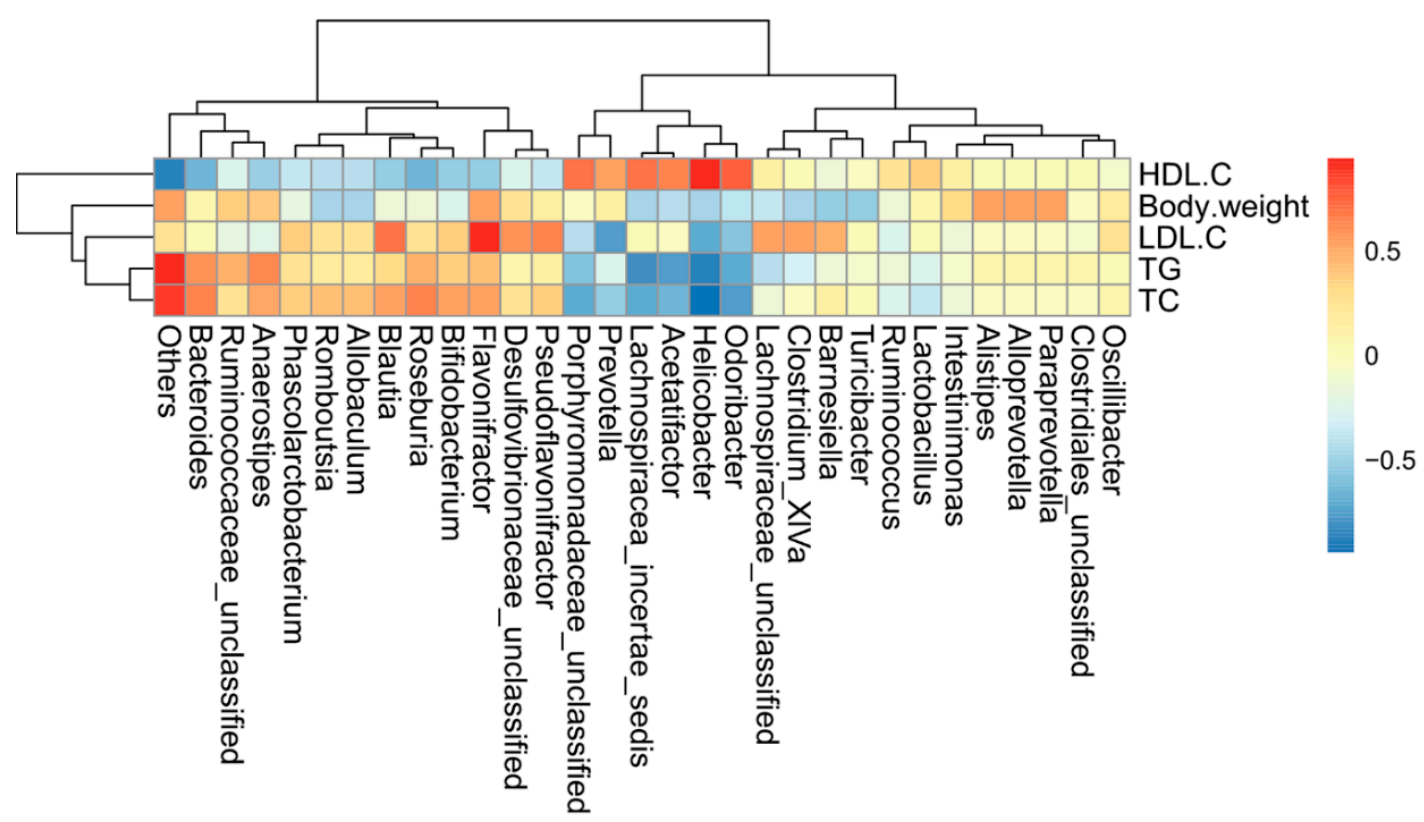

Figure 6. Statistical Spearman's correlations between the caecal microbiota of significant differences and lipid metabolic parameters in SPPH, HFD, and NFD groups. The intensity of the color represents the degree of association between caecal microbiota of significant differences and MetS-associated parameters.

\section{Discussion}

As important components of metabolic syndrome, obesity and hyperlipidemia are present in the majority of patients with cardiovascular and cerebrovascular diseases, resulting in high mortality rates [31]. The prevalence of obesity in recent decades can be largely attributed to changes in food habits and increased sedentary life style. Despite the rapidly growing recognition of hepatic steatosis, therapy or prevention of the disease remains less available [32]. In view of the very limited availability of FDA approved anti-obesity drugs and considering their side effects, it is quite necessary to find novel and effective natural product-based drugs to combat obesity.

Among different targets to treat obesity, the ones that can interfere with the process of lipid mobilization are fundamental [33-35]. Previous studies have shown that TC, TG, HDL-c, and LDL-c are strongly correlated with the prevalence and incidence of metabolic syndrome and cardiovascular diseases [36,37]. The serum LDL-C and TG levels are considered key risk indicators for atherosclerotic cardiovascular disease [38]. An evidence-based study has also shown that lowering the serum LDL-C and TG levels can effectively ameliorate the risk of vascular disease and reduce the incidence of acute coronary events [39]. AST and ALT are investigated as markers of liver damage, regarding the changes in lipid of HFD-fed rodents [40]. Measurement of liver damage caused by fat accumulation is important for diagnosis of non-alcoholic fatty liver disease (NAFLD). Obesity causes altered function of adipocytes, leading to expanded adipocyte mass and increased release of FFAs in the blood. Excess accumulation of TG in the liver results in significant and more abundant lipid accumulation [41,42]. In our experiment, we established an animal model of HFD-induced obesity, which is considered to be a good model as it has been reported to bear close resemblance to human obesity [43]. Consistent with a previous study, we showed that HFD resulted in significantly increased body weight, elevated levels of TC, TG, LDL-C, AST, and ALT, and decreased HDL-c level in serum and liver. Moreover, there were fat accumulation and massive accumulation of lipid droplets in the liver. However, the weight-losing effect of SPPH treatment was significant on HFD-fed rats, which might be associated with enhanced energy metabolism [44]. These results provided new insights into the anti-obesity effect of SPPH. In addition, SPPH treatment resulted in decreased levels of TC, TG, HDL-c, and LDL-c in serum and 
liver compared with the HFD group, which were similar to the levels of the ND group. Meanwhile, SPPH treatment also resulted in a significant decrease in hepatocyte steatosis, lipid droplets, and hepatic lipid accumulation. We showed a significantly increased number and size of fatty hepatocytes upon HFD administration, while such changes returned to the normal levels in the SPPH group [45]. SPPH have anti-obesity and hepatoprotective capacities [46]. Previous studies have shown that body weight is reduced by extracts of a few plant species, including leafs of Murraya koenigii and resin of Commiphora mukul, in HFD-fed rats [47-50]. These results demonstrated SPPH could be used as an effective agent in ameliorating the HFD-induced effects.

We investigated the expressions of several genes related to fatty acid transport (PPAR $\alpha$ and ACC) and lipid metabolism, including lipogenesis (SREBP-1c and PPAR $\gamma$ ) and $\beta$-oxidation (AMPK), to explore the possible mechanism of SPPH in decreasing accumulation of liver lipids. Several studies have demonstrated that SREBP-1c, a major transcription factor involved in hepatic lipogenesis, plays an important role, leading to increased fatty acid synthesis as a result of the induction of ACC [51,52]. One study has reported that the expression of SREBP-1c is positively correlated with the degree of hepatic steatosis in NAFLD patients [53]. Results of the current study showed that the expression of SREBP-1c was significantly lower in the liver of the NFD group compared with the HFD-fed rats. Consistent with a previous study, SPPH treatment effectively inhibited such increased expression of SREBP-1c. The expression of SREBP-1c transcriptional target ACC was strongly correlated with the SREBP-1c expression, suggesting that suppression of ACC contributed to a reduction in lipid accumulation in fatty liver [51,52]. SPPH treatment decreased the HFD-induced high expression of ACC. Taken together, these results demonstrated that SPPH down-regulated the expressions of lipogenesis-related genes in HFD-induced fatty liver. Of particular importance, PPAR $\alpha$ is a ligand-activated transcription factor, and its activation induces the expressions of several genes involved in fatty acid oxidation at the mRNA level to reduce the circulating lipid levels [54]. Meanwhile, the activation of intestinal fatty acid oxidation by PPAR $\alpha$ agonist bezafibrate suppresses postprandial lipidaemia in rats [46], and PPAR $\alpha$ reduces the plasma TG and TC levels. Our current results showed that PPAR $\alpha$ expression was significantly lower in the HFD group compared with the NFD group, while it was increased by SPPH treatment. A recent report has indicated that PPAR $\alpha$ also modulates the expressions of lipogenic genes in liver, such as ACC, which are closely related to fatty acid synthesis and oxidation in hepatic steatosis in HFD-fed animals [55]. Liver adipose tissues are associated with the pathogenesis of metabolic syndrome [56]. Collectively, our results showed a significantly smaller liver lipid droplet area in the SPPH group, accompanied by an increased expression of PPAR $\alpha$ and decreased expressions of SREBP-1c and ACC. Fat cell formation or adipogenesis is a differentiation process, by which undifferentiated preadipocytes are converted in to fully differentiated adipocytes [57]. Adipose tissue is a dynamic organ, the mass of which changes during a lifetime in response to metabolic requirements of the animal, thus playing an important role in energy balance. Particularly, SREBP-1c, one of the pro-adipogenic transcription factors, induces the PPAR $\gamma$ expression and regulates the expressions of AMPK [58-60]. However, we clearly showed that administration of SPPH considerably affected SREBPs. SREBPs are another family of transcription factors, but they are majorly involved in the regulation of lipid homeostasis by activating the expressions of genes required for the synthesis and uptake of cholesterol, fatty acid, and triglycerides. Previous studies have suggested that AMPK plays a role in the physiological regulation of fatty acid and glucose metabolism as well as in the regulation of appetite [61]. In our study, we found that AMPK was down-regulated in the HFD group. However, such alterations in the HFD-fed group were considerably reversed by the SPPH treatment. These results suggested that SPPH could decrease body weight and fat mass through down-regulation of SREBP-1c and PPAR $\gamma$, which in turn resulted in inhibited expressions of lipogenic enzymes. Furthermore, we proved the anti-obesity activity of SPPH as evidenced from the reduced size of adipocytes in the SPPH group. Previous studies have demonstrated the anti-diabetic and anti-hyperlipidemic activities of elllagic acid, betulinic acid, and arjunolic acid from different plant sources [62,63]. 
Gut microbiota can directly affect blood cholesterol levels with its effects on the development of atherosclerosis, and several studies have proved the effects of an HFD on gut microbiota $[64,65]$. We compared the faecal and caecal microbiota of rats in three different groups to elucidate the precise underlying mechanism of improved hyperlipidaemia by SPPH. SPPH treatment increased the abundances of Peptococcaceae, Prevotella, Alistipes, Porphyromonadaceae, Barnesiella, and Parasutterella. Prevotella and Alistipes showed a negative correlation with the levels of serum TG, TC, and LDL-c, while they were positively correlated with the serum HDL-c level. The enterotype-like clusters driven by Alistipes and Prevotella (P-type) microbiota are characterized by a more conserved bacterial community [66]. The latest study has shown that there is a positive correlation between bile acid and Prevotella. Prevotella regulates lipid levels by altering the bile acid metabolism to change the blood lipid levels [67]. Our findings were consistent with a previous study. The abundances of Alistipes and Prevotella were increased by SPPH treatment. On the other hand, we know that the genus, Barnesiella, a family of Porphyromonadaceae, is part of the gut microbiota. In addition to the family, porphyrinaceae, the Bacteroidetes include the families, Bacteroidaceae and Prevotellaceae. Moreover, Barnesiella spp. regulates the composition of microbiota and optimizes host survival [68]. Besides, Alloprevotella and Ruminococcus were also enriched by SPPH treatment. These bacteria are short-chain fatty acid (SCFA) producers and negatively correlated with NAFLD and LMD [69]. Anaerobic bacteria are colonized in the cecum and colon, and they can ferment the non-digestible carbohydrate into SCFAs, such as propionate and butyrate. The SCFAs can be directly absorbed by the intestine and regulate the energy metabolism and insulin sensitivity of peripheral tissues via $G$ protein-coupled receptors [70]. In addition, our findings showed that SPPH decreased the proportion of Firmicutes and increased the proportion of Bacteroidetes in caecal contents. These results were in accordance with the theory that the proportion of body fat is positively correlated with the abundance of Firmicutes in the gut microbiota in humans and mice. Besides, changes in body weight and serum LDL-c levels were positively correlated with Firmicutes. There were increased proportions of Porphyromonadaceae, which has been previously associated with NAFLD, atherosclerosis, and diabetes [71]. In addition to the increase in health-promoting bacteria, a loss of HFD-enriched microbes (Clostridium XVIII) was also observed in the SPPH-triggered alleviation of hyperlipidaemia. Turicibacter, belonging to the phylum, Firmicutes, may have a negative effect on gut health and the metabolic parameters in serum, such as TC and TG. Previous studies have shown that the abundance of Clostridium XVIII is increased in individuals with gastrointestinal disorders and dysfunctions, and such increased abundance of Clostridium may be induced by obesity-related metabolic disorders or pro-inflammatory responses [72]. However, the relationship between Clostridium XVIII and lipid metabolism remains largely unexplored. Therefore, our data directly proved that the HFD could cause colonic pathology and inflammation in HFD-fed rats, which might be associated with a proportional increase in Clostridium XVIII. In summary, we provided convincing evidence for the potential use of SPPH in hyperlipidemia and demonstrated that potent modulation of the intestinal microbiota during attenuation of metabolic disease was associated with its beneficial effects. Figure S7 illustrates the mechanism by which SPPH reduced blood lipid levels. SPPH had the potential to ameliorate LMD, in part through modulating specific gut microbiota and regulating the expressions of the genes involved in lipid and cholesterol metabolism at the mRNA level. Therefore, SPPH might be beneficial for anti-hyperlipidemia, leading to the reduced risk of LMD.

\section{Materials and Methods}

\subsection{Chemicals and Materials}

In the present study, the air-dried and clean Spirulina platensis powder with a protein content of $60 \%$ was obtained from King Dnarmsa Spirulina Co., Ltd. (Fuqing, China). Protamex was purchased from Suo Laibao Biotechnology Co., Ltd. (Beijing, China). 


\subsection{Preparation of SPPH}

Spirulina platensis powder and $95 \%$ ethanol $\left(1: 10, W_{\text {powder }}: V_{\text {ethanol }}\right)$ were mixed at $45^{\circ} \mathrm{C}$ for $0.5 \mathrm{~h}$, the macerate was filtered through Whatman filter paper No 3, then the supernatant was discarded in order to remove soluble substances in organic reagents, and the solid material was dried [73]. The dried solid material was soaked in $55 \%$ ethanol at a ratio of $1: 10(w / v)$ at $45{ }^{\circ} \mathrm{C}$ for $0.5 \mathrm{~h}$, the macerate was filtered through Whatman filter paper No 3 , the supernatant was then discarded in order to remove soluble substances in organic reagents, and the solid material was dried. The dried solid material was soaked in distilled water at a ratio of $1: 10(w / v)$ at $45{ }^{\circ} \mathrm{C}$ for $0.5 \mathrm{~h}$, the macerate was filtered through Whatman filter paper No 3, the supernatant was then discarded in order to remove soluble substances in water, and the solid material was dried. The dried solid material was soaked in distilled water at a ratio of 1:10 $(w / v)$, and the $\mathrm{pH}$ was adjusted to 7.5 prior to the addition of protamex (E:S = 1:50) (Enzyme: Substrate $=1: 50(\mathrm{~m} / \mathrm{m})$ ) and maintained at $\mathrm{pH} 7.5$ and $45^{\circ} \mathrm{C}$. After $1 \mathrm{~h}$, the hydrolyzed solution was bathed in boiling water for $10 \mathrm{~min}$ to inactivate the enzyme [74]. The supernatant was passed through a $100-\mu \mathrm{m}$ mesh in order to remove solids in suspension. Subsequently, the supernatant was concentrated at $6000 \mathrm{~g}$ and $4{ }^{\circ} \mathrm{C}$ for $30 \mathrm{~min}$ in order to remove undigested proteins and inactivate the enzyme. Finally, the supernatant of SPPH containing the target Spirulina platensis peptides was collected and stored at $-20{ }^{\circ} \mathrm{C}$ prior to further analysis. The obtained dry substance was named as SPPH. Meanwhile, Spirulina platensis peptides were prepared under the conditions as follows. The peptide in the sample was dissolved, followed by a desalting procedure. First, $300 \mu \mathrm{L}$ of $50 \mathrm{mM}$ ammonium bicarbonate was added to SPPH, the mixture was shaken and centrifuged at $12,000 \mathrm{~g}$ for $10 \mathrm{~min}$, and the supernatant was transferred to a new EP tube. Then, $300 \mu \mathrm{L}$ of $50 \mathrm{mM}$ ammonium bicarbonate was added to the sample, the peptide was reconstituted once, and the supernatants were combined for two times. Second, $1 \mathrm{~mL}$ of $50 \%$ acetonitrile was added to the Bond Elut C18 desalting column and allowed to flow slowly through the desalting column. The desalting column was washed four times by adding $2 \%$ acetonitrile $(0.1 \%$ formic acid) to a desalting column. The sample was made up to $1 \mathrm{~mL}$ with $2 \%$ acetonitrile ( $0.1 \%$ formic acid) and loaded onto a desalting column. The desalting column was washed four times with $2 \%$ acetonitrile $(0.1 \%$ formic acid). The sample was eluted by adding $700 \mu \mathrm{L}$ of $60 \%$ acetonitrile $(0.1 \%$ formic acid) to the desalting column, and the eluate was collected. The sample after centrifugation and concentration was re-dissolved in the RPLC mobile phase A ( $0.1 \%$ formic acid, $2 \%$ acetonitrile/water) and bottled for online HPLC-MS/MS analysis [74].

\subsection{HPLC-MS/MS Analysis of SPPH}

The liquid phase was an ultra-fast liquid chromatograph Nexera XR (Shimadzu Corporation, Japan). The analytical column was a Waters BEH C18 column $(1.7 \mu \mathrm{m}, 2.1 \times 50 \mathrm{~mm})$ (Macherey-Nagel, Düren, Germany). The mobile phase consisted of binary mixture of $0.1 \%(v / v)$ formic acid (solvent A) and acetonitrile (solvent $B$ ). The flow rate was set at $0.3 \mathrm{~mL} / \mathrm{min}$. Elution gradient was as follows: 0-1 $\min : 5 \%$ B $, 1-7 \mathrm{~min}: 5-60 \% \mathrm{~B}, 7-8 \mathrm{~min}: 60-80 \% \mathrm{~B}, 8-10 \mathrm{~min}: 5 \% \mathrm{~B}$. The column temperature was set at $35{ }^{\circ} \mathrm{C}$. The injection volume was $10 \mu \mathrm{L}$. TripleTOF 5600 system (AB SCIEX) equipped with a positive electrospray ionization source (ESI) was used. The MS parameters were set as follows: Spray voltage of $5600 \mathrm{~V}$, air curtain pressure of $35 \mathrm{PSI}$, atomization pressure of 55 PSI, auxiliary gas of $50 \mathrm{PSI}$, ion source temperature of $500{ }^{\circ} \mathrm{C}$, and solvent voltage of $100 \mathrm{~V}$. The mass spectrometry scanning mode was the information-dependent acquisition mode (IDA Information Dependent Analysis). The first-level TOF-MS scanning ranged from 300-1500 m/z, the cumulative time was $250 \mathrm{~ms}$, and the maximum charge (2+ to $5+$ ) was 35 for each IDA cycle and a secondary map with a single-second count greater than $160 \mathrm{cps}$. The cumulative time for each secondary map was $60 \mathrm{~ms}$, and the secondary mass spectrum scanning ranged from 100-500 m/z. Each cycle time was fixed at $2.5 \mathrm{~s}$. The collision chamber energy setting was applied to all precursor ion collision-induced dissociation (CID), and the collision energy was automatically optimized. The dynamic exclusion was set to $6 \mathrm{~s}$. The original wiff map file collected by mass spectrometry was processed and searched by PEAKS Studio 8 software (Bioinformatic Solutions Inc., Waterloo, ON, Canada). The databases 
were Spirulina platensis protein databases under Uniprot. The search parameters were set as follows: Cysteine alkylation to iodoacetamide modification, trypsin digestion, primary mass spectrometry mass tolerance was $20 \mathrm{ppm}$, secondary mass spectrometry was $0.1 \mathrm{Da}$, and peptide score $(-10 \operatorname{lgP})$ greater than or equal to 20 was considered reliable.

\subsection{Animals and Experimental Design}

Thirsty healthy male Wistar rats aged 4 weeks were taken from Shandong Laboratory Animal Center of Shandong Academy (Shandong, China). All animal experiments procedures received care according to institutional guidelines, and all of the experiments were approved by the Fuzhou General Hospital Institutional Animal Care and Use committee. (IACUC approval no. CGU11-119). The animals were housed in a temperature-controlled room at $25 \%$ and $60 \%$ relative humidity with ad libitum access to food and distilled water and maintained on a reverse $12 \mathrm{hlight} /$ dark cycle during the experimental period. After 1 week of the acclimation period, rats were randomly divided into the following three groups stochasticly, normal fat diet (NFD) group (rats fed NFD, $n=8$ ), high-fat diet (HFD) group (rats fed HFD, $n=8$ ), and SPPH group (HFD-fed rats treated with SPPH, $n=8$ ), by using a method described previously [75] Rats in the NFD group were given a basal diet $(13.5 \%$ energy from fat; Lab Diet 5001; Laboratory Rodent Diet), and rats in the HFD and SPPH groups were given HFD (67\% normal diet, 20\% sugar, 10\% lard, and 3\% cholesterol). NFD and HFD groups were fed basal diet and HFD with $2 \mathrm{~mL} 0.9 \%$ saline orally, respectively, while the SPPH group was fed HFD with $2 \mathrm{~mL} \mathrm{SPPH}$ extract $(150 \mathrm{mg} / \mathrm{kg}$.day) orally through gavage at the same time in the morning. The compositions of the experimental diets were based on the AIN-93 semisynthetic diet (American Institute of Nutrition, 1993, 1994).

\subsection{Serum Samples Preparation}

After 8 weeks of the experiment period, the rats were sacrificed following a $12 \mathrm{~h}$ fast and were anesthetized by intraperitoneal injection using ketamine hydrochloride, blood was collected from the heart, and the sample was transferred to a centrifuge tube. Serum was separated at 12,000 $\mathrm{g}$ for $10 \mathrm{~min}$ at $4{ }^{\circ} \mathrm{C}$ and was then stored at $-80^{\circ} \mathrm{C}$ until analysed.

\subsection{Liver Homogenate Preparation}

Liver was dissected, weighed, and cut into several sections, washed in saline solution $(0.1 \mathrm{~g}$ of liver tissue was mixed with $0.9 \mathrm{~mL}$ of saline), dried, and immediately frozen and stored at $-80^{\circ} \mathrm{C}$ livers, after snap-freezing in liquid nitrogen. After centrifugation at $8000 \mathrm{~g}$ for $15 \mathrm{~min}$ at $4{ }^{\circ} \mathrm{C}$, the supernatant was taken for analysis.

\subsection{Biochemical Assays of Serum and Liver Tissue}

The level of TC, TG, HDL-c, and LDL-c in rats' serum using the assay kits (Nanjing Jiancheng Institute of Biotechnology, Nanjing, China) [76]. The level of TC, TG, HDL-c, LDL-c, ALT, and AST were measured in liver tissue using the corresponding assay kit. (Nanjing Jiancheng Institute of Biotechnology, Nanjing, China).

\subsection{Liver Histopathological Analysis}

The liver tissues were removed from each mice and samples were subsequently fixed in $4 \% 128$ $(v / v)$ paraformal dehyde/PBS then treated with ethanol solution. After that, all liver samples were fixed in paraformal dehyde and embedded in paraffin for staining with hematoxylin and 129 eosin or Oil red $\mathrm{O}$, respectively. The slices were sectioned at $5 \mu \mathrm{m}$. The sections were observed for morphological evaluation at high magnification under an optical microscope (Nikon Eclipse TE2000-U, Nikon, Tokyo, Japan) $[77,78]$. 


\section{9. mRNA Preparation and Gene Expression}

Total tissue and cellular RNA was prepared by using Sepasol Super-I (Nacalai Tesque) according to the manufacturer's instructions. cDNA was synthesized using PrimeScript ${ }^{\mathrm{TM}}$ RT reagent Kit with gDNA Eraser (Takara, Japan). RT-qPCR of AMPK- $\alpha$, SREBP-1c, HMG-CoA, PEPCK, ACC, and control $\beta$-actin use the SYBR ${ }^{\circledR}$ Premix Ex Taq ${ }^{\text {TM }}$ II (Takara, Japan) to Monitor Gene Expression Levels. Following is a list of specific primers: AMPK- $\alpha, 5^{\prime}$-ATTTGCCCAGTTACCTCTTTCC- $3^{\prime}$, R: $5^{\prime}-$ GCTTGGTTCATTATTCTCCGAT-3'; SREBP-1c, F: 5'-GCTGTTGGCATCCTGCTATC-3', R: 5'-TAGC TGGAAGTGACGGTGGT-3'); HMG-CR, F: 5'-AGTGGTGCGTCTTCCTCG-3' , R: 5'-CGAATCTGCTG

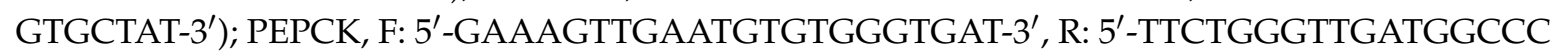
TTA-3'; ACC, F: 5'-ACACTGGCTGGCTGGACAG-3' ${ }^{\prime}$ R: 5'-CACACAACTCCCAACATGGTG-3' ${ }^{\prime}$, and control $\beta$-actin, F: 5'-ACGTCGACATCCGCAAAGACCTC-3', R: 5'-TGATCTCCTTCTGCATCCGGT CA-3'. Amplifications were performed using the AB7300 Real-Time PCR system (Waltham, USA). The conditions were as follows: Initial activation at $95^{\circ} \mathrm{C}$ for $30 \mathrm{~s}$, followed by 40 cycles of denaturation at $95{ }^{\circ} \mathrm{C}$ for $5 \mathrm{~s}$, annealing at $60{ }^{\circ} \mathrm{C}$ for $31 \mathrm{~s}$, and extension at $72{ }^{\circ} \mathrm{C}$ for $30 \mathrm{~s}$. All data indicating mRNA expression levels are presented as a ratio relative to a control in each experiment Using an RNA extraction kit (Takara, Tokyo, Japan) to extract total RNA from the liver tissues, determination of the relative levels of target mRNAs was performed using the $2^{-\Delta \Delta C t}$ method and normalization [79].

\subsection{Dynamic Profile of Intestinal Microflora in Response to SPPH}

Caecal contents samples were collected at 8 weeks from rats from different groups, using a QIAamp-DNA stool mini kit (Qiagen, Hilden, Germany) to extract Metagenomic DNA from caecal contents of rats. The V3-V4 hypervariable regions of $16 \mathrm{~S}$ rRNA gene from caecal microbiota were amplified using specific primers (F: $5^{\prime}$-CCTACGGRRBGCASCAGKVRVGAAT- $3^{\prime}$ and R: $5^{\prime}$-GGACTACNVGGGTWTCTAATCC-3') [80]. Sequencing was performed using a $2 \times 300$ paired-end (PE) configuration. Analysis was performed by MiSeq control software. The initial classification analysis was conducted on an Illumina's Base Space cloud computing platform.

\section{Bioinformatics Analysis}

High-quality sequences were assigned to samples based on barcodes. In order to study the diversity information of species composition, the valid sequences were denoised. Results were generated by using Usearch (Version 7.1, http:/ / drive5.com/uparse/) with 3\% disagreement [81].

\section{Statistical Analysis}

The data for each group was expressed as mean \pm standard deviation (SD). Statistical significance was measured using one-way analysis of variance (ANOVA). Statistical significance is expressed by a $p$-value less than 0.05 . Relationships between gut microbiota composition and biochemical indicators in serum were determined using the Spearman's rank correlation method.

\section{Conclusions}

Taken together, SPPH was able to affect the lipid metabolism of HFD-fed Wistar rats. After 8 weeks of SPPH treatment, body weight was increased, the levels of TC, TG, LDL-c, AST, and ALT in serum and liver were elevated, the liver steatosis was reduced, and the level of HDL-c was induced. Moreover, SPPH reduced the incidence of liver lesions and improved hepatocyte abnormality. SPPH supplementation directly affected lipid metabolism in the liver by influencing relational mRNA expression and affecting the gut microbiome by HFD-induced lipid metabolism disorder in rats. Collectively, we, for the first time, characterized a new potential therapeutic role of SPPH. However, we should conduct an in-depth analysis of changes in gut microbiota, and its underlying molecular mechanism upon SPPH supplementation should also be further assessed. 
Supplementary Materials: The following are available online at http://www.mdpi.com/1422-0067/19/12/ 4023/s1, Figure S1: Representative chromatograms and MS/MS spectra of high abundance peptide (MQGPNY); Figure S2: Representative chromatograms and MS/MS spectra of high abundance peptide (LSPGELDRIKS); Figure S3: Representative chromatograms and MS/MS spectra of high abundance peptides (KFPYTTQ); Figure S4: Representative chromatograms and MS/MS spectra of high abundance peptides (VVFVPSN); Figure S5: Representative chromatograms and MS/MS spectra of high abundance peptides (LVTPSMG); Figure S6: Representative chromatograms and MS/MS spectra of low abundance peptides (IGDNPNPASVK); Figure S7: Summary of the mechanism underlying the preventive effects of SPPH on LMD; Table S1: Peptide profile of SPPH identified by HPLC-MS/MS.

Author Contributions: The authors declare that there is no conflict of interest that could be perceived as prejudicing the impartiality of the research reported. P.H. performed the research work, interpreted the results, critically analyzed the important data and drafted the manuscript. Z.Y. and Y.X. contributed to figure drawing and data analysis. B.L. and L.Z. designed the whole study and drafted the manuscript and gave the final approval to the version of the manuscript that is being sent for consideration for publication. All authors read and approved the final manuscript.

Funding: This research was funded by the National Natural Science Foundation of China (31501432), the Science Foundations of Fujian Agriculture and Forestry University (XJQ201608), the project of Marine High-technology Industry development of Fujian (No.2014-17) and the 13th Five-year Plan on Fuzhou Marine Economic Innovation and Development Demonstration Project.

Conflicts of Interest: The authors declare that they have no conflicts of interest.

Ethical Approval: This article does not contain any studies with human participants performed by any of the authors. All animal experiments procedures received care according to institutional guidelines, and all of the experiments were approved by the Fuzhou General Hospital Institutional Animal Care and Use committee (IACUC approval no. CGU11-119).

\section{References}

1. Abliz, A.; Aji, Q.; Abdusalam, E.; Sun, X.; Abdurahman, A.; Zhou, W.; Moore, N.; Umar, A. Effect of Cydonia oblonga Mill. leaf extract on serum lipids and liver function in a rat model of hyperlipidaemia. J. Ethnopharmacol. 2014, 151, 970-974. [CrossRef] [PubMed]

2. Fidèle, N.; Joseph, B.; Emmanuel, T.; Théophile, D. Hypolipidemic, antioxidant and anti-atherosclerogenic effect of aqueous extract leaves of Cassia. occidentalisLinn (Caesalpiniaceae) in diet-induced hypercholesterolemic rats. BMC Complement. Altern. Med. 2017, 17, 76-86. [CrossRef] [PubMed]

3. Yuan, F.; Dong, H.; Fang, K.; Gong, J.; Lu, F. Effects of green tea on lipid metabolism in overweight or obese people: A meta-analysis of randomized controlled trials. Mol. Nutr. Food Res. 2017, 62, 1601122-1601134. [CrossRef] [PubMed]

4. Kwon, E.Y.; Jung, U.J.; Park, T.; Yun, J.W.; Choi, M.S. Luteolin attenuates hepatic steatosis and insulin resistance through the interplay between the liver and adipose tissue in mice with diet-induced obesity. Diabetes 2015, 64, 1658-1669. [CrossRef] [PubMed]

5. Hurt, R.T.; Edakkanambeth, V.J.; Ebbert, J.O. New pharmacological treatments for the management of obesity. Curr. Gastroenterol. Rep. 2014, 16, 394. [CrossRef] [PubMed]

6. Rodgers, R.J.; Tschöp, M.H.; Wilding, J.H. Anti-obesity drugs: Past, present and future. Dis. Model. Mech. 2012, 5, 621-626. [CrossRef] [PubMed]

7. Tung, Y.T.; Chen, H.L.; Wu, H.S.; Ho, M.H.; Chong, K.Y.; Chen, C.M. Kefir Peptides Prevent Hyperlipidemia and Obesity in High Fat Diet-Induced Obese Rats via Lipid Metabolism Modulation. Mol. Nutr. Food Res. 2017, 62. [CrossRef]

8. Baldassano, S.; Amato, A.; Caldara, G.F.; Mulè, F. Glucagon-like peptide-2 treatment improves glucose dysmetabolism in mice fed a high-fat diet. Endocrine 2016, 54, 1-9. [CrossRef]

9. Kusumoto, Y.; Irie, J.; Iwabu, K.; Tagawa, H.; Itoh, A.; Kato, M.; Kobayashi, N.; Tanaka, K.; Kikuchi, R.; Fujita, M.; et al. Bile acid binding resin prevents fat accumulation through intestinal microbiota in high-fat diet-induced obesity in mice. Metab. Clin. Exp. 2017, 71, 1-6. [CrossRef]

10. Zhang, W.L.; Zhu, L.; Jiang, J.G. Active ingredients from natural botanicals in the treatment of obesity. Obes. Rev. 2015, 15, 957-967. [CrossRef]

11. Le, T.M.; Knulst, A.C.; Röckmann, H. Anaphylaxis to Spirulina confirmed by skin prick test with ingredients of Spirulina tablets. Food Chem. Toxicol. 2014, 74, 309-310. [CrossRef] [PubMed] 
12. Piñero Estrada, J.E.; Bermejo, B.P.; Am, V.D.F. Antioxidant activity of different fractions of Spirulina platensis protean extract. Farmaco 2001, 56, 497-500. [CrossRef]

13. Abdelkhalek, N.K.; Ghazy, E.W.; Abdel-Daim, M.M. Pharmacodynamic interaction of Spirulina platensis and deltamethrin in freshwater fish Nile tilapia, Oreochromis niloticus: Impact on lipid peroxidation and oxidative stress. Environ. Sci. Pollut. Res. 2015, 22, 3023-3031. [CrossRef] [PubMed]

14. Mao, T.K.; Van, D.W.J.; Med, M.E.J. Effect of spirulina on the secretion of cytokines from peripheral blood mononuclear cells. Food 2000, 3, 135-175. [CrossRef] [PubMed]

15. Khan, Z.; Bhadouria, P.; Bisen, P.S. Nutritional and therapeutic potential of Spirulina. Curr. Pharm. Biotechnol. 2005, 6, 373-379. [CrossRef] [PubMed]

16. Abdeldaim, M.M.; Farouk, S.M.; Madkour, F.F.; Azab, S.S. Anti-inflammatory and immunomodulatory effects of Spirulina platensis in comparison to Dunaliella salina in acetic acid-induced rat experimental colitis. Immunopharmacol. Immunotoxicol. 2015, 37, 126-139. [CrossRef]

17. Upasan, C.D.; Balaraman, R. Protective effect of Spirulina on lead induced deleterious changes in the lipid peroxidation and endogenous antioxidants in rats. Phytother. Res. 2010, 17, 330-334. [CrossRef]

18. Upasani, C.D.; Khera, A.; Balarama, R. Effect of lead with vitamin E, C, or Spirulina on malondialdehyde, conjugated dienes and hydroperoxides in rats. Indian J. Exp. Biol. 2001, 39, 70-74.

19. Zhang, H.Q.; Lin, A.P.; Sun, Y.; Deng, Y.M. Chemo- and radio-protective effects of polysaccharide of Spirulina platensis on hemopoietic system of mice and dogs. Acta Pharmacol. Sin. 2001, 22, 1121-1124.

20. Iwata, K.; Inayama, T.; Kato, T. Effects of Spirulina platensis on plasma lipoprotein lipase activity in fructose-induced hyperlipidemic rats. J. Nutr. Sci. Vitaminol. 1990, 36, 165. [CrossRef]

21. Pérez-Vega, J.; Olivera-Castillo, A.L.; Gómez-Rui, J.Á.; Hernández-Ledesma, B. Release of multifunctional peptides by gastrointestinal digestion of sea cucumber (Isostichopus badionotus). J. Funct. Foods 2013, 5, 869-877. [CrossRef]

22. Balakumar, P.; Balakumar, M.; Arora, K.; Singh, M. Emerging role of PPAR ligands in the management of diabetic nephropathy. Pharmacol. Res. 2009, 60, 170-173. [CrossRef] [PubMed]

23. Balakumar, P.; Rose, M.; Singh, M. PPAR ligands: Are they potential agents for cardiovascular disorders? Pharmacology 2007, 80, 1-10. [CrossRef] [PubMed]

24. Contreras, A.V.; Torres, N.; Tovar, A.R. SPAR- $\alpha$ as a key nutritional and environmental sensor for metabolic adaptation. Advances in Nutrition: An International. Rev. J. 2013, 4, 439-452. [CrossRef]

25. Yuan, H.D.; Kim, S.J.; Quan, H.Y.; Im, B.O.; Chung, S.H.; Lee, K.H.; Cho, D.H.; Cho, J.Y. Ginseng Leaf Extract Prevents High Fat Diet-Induced Hyperglycemia and Hyperlipidemia through AMPK Activation. J. Ginseng. Res. 2010, 34, 369-375. [CrossRef]

26. Velagapudi, V.R.; Hezaveh, R.; Reigstad, C.S.; Gopalacharyulu, P.; Yetukuri, L.; Islam, S.; Felin, J.; Perkins, R.; Borén, J.; Oresic, M.; et al. The gut microbiota modulates host energy and lipid metabolism in mice. J. Lipid Res. 2010, 51, 1101-1112. [CrossRef] [PubMed]

27. Lakhan, S.E.; Kirchgessner, A. Gut microbiota and sirtuins in obesity-related inflammation and bowel dysfunction. J. Transl. Med. 2011, 9, 202-208. [CrossRef] [PubMed]

28. Saad, M.J.; Santos, A.; Prada, P.O. Linking Gut Microbiota and Inflammation to Obesity and Insulin Resistance. Physiology 2016, 31, 283-293. [CrossRef] [PubMed]

29. Turnbaugh, P.J.; Ridaura, V.K.; Faith, J.J.; Rey, F.E.; Knight, R.; Gordon, J.I. The Effect of Diet on the Human Gut Microbiome: A Metagenomic Analysis in Humanized Gnotobiotic Mice. Sci. Transl. Med. 2009, 1, 6. [CrossRef] [PubMed]

30. Gu, Y.; Wu, J. LC-MS/MS coupled with QSAR modeling in characterising of angiotensin I-converting enzyme inhibitory peptides from soybean proteins. Food Chem. 2013, 141, 2682-2690. [CrossRef] [PubMed]

31. Qi, S.Z.; Li, N.; Tuo, Z.D.; Li, J.L.; Xing, S.S.; Li, B.B.; Zhang, L.; Lee, H.S.; Chen, J.G.; Cui, L. Effects of Morus root bark extract and active constituents on blood lipids in hyperlipidemia rats. J. Ethnopharmacol. 2016, 180, 54-59. [CrossRef]

32. Song, Y.; Lee, S.J.; Jang, S.H.; Ji, H.H.; Song, Y.M.; Ko, Y.G.; Kim, H.D.; Min, W.; Kang, S.N.; Cho, J.H. Sasa borealis stem extract attenuates hepatic steatosis in high-fat diet-induced obese rats. Nutrients 2014, 6, 2179-2195. [CrossRef] [PubMed]

33. Lópezmartí, J.; Díazsilva, M.; Salas, A.; Del, M.G.M.; Fernández-López, J.; Remesar, X.; Alemany, M.; Fernándezlópez, J. Oleoyl-estrone induces the massive loss of body weight in Zucker fa/fa rats fed a high-energy hyperlipidic diet. J. Nutr. Biochem. 2000, 11, 530-535. [CrossRef] 
34. Kusunoki, M.; Hara, T.; Tsutsumi, K.; Nakamura, T.; Miyata, T.; Sakakibara, F.; Sakamoto, S.; Ogawa, H.; Nakaya, Y.; Storlien, L.H. The lipoprotein lipase activator, NO-1886, suppresses fat accumulation and insulin resistance in rats fed a high-fat diet. Diabetologia 2000, 43, 875-880. [CrossRef] [PubMed]

35. Woo, M.N.; Bok, S.H.; Lee, M.K.; Kim, H.J.; Jeon, S.M.; Do, J.M.; Shin, S.K.; Ha, T.Y.; Choi, M.S. Anti-obesity and hypolipidemic effects of a proprietary herb and fiber combination (S\&S PWH) in rats fed high-fat diet. J. Med. Food 2008, 11, 169-178. [CrossRef] [PubMed]

36. Koyama, Y.; Maebara, Y.; Hayashi, M.; Nagae, R.; Tokuyama, S.; Michinaga, S. Endothelins reciprocally regulate VEGF-A and angiopoietin-1 production in cultured rat astrocytes: Implications on astrocytic proliferation. Glia 2012, 60, 1954-1963. [CrossRef]

37. Shearer, K.D.; Fragoso, Y.D.; Clagett-Dame, M.; Mccaffery, P.; Tokuyama, S.; Michinaga, S. Astrocytes as a regulated source of retinoic acid for the brain. Glia 2012, 60, 1964-1976. [CrossRef]

38. Deedwania, P.C.; Pedersen, T.R.; Demicco, D.A.; Breazna, A.; Betteridge, D.J.; Hitman, G.A.; Durrington, P.; Neil, A. Differing predictive relationships between baseline LDL-C, systolic blood pressure, and cardiovascular outcomes. Int. J. Cardiol. 2016, 222, 548-556. [CrossRef]

39. Wada, H.; Dohi, T.; Miyauchi, K.; Shitara, J.; Endo, H.; Doi, S.; Konishi, H.; Naito, R.; Tsuboi, S.; Ogita, M.; et al. Pre-procedural neutrophil-to-lymphocyte ratio and long-term cardiac outcomes after percutaneous coronary intervention for stable coronary artery disease. Atherosclerosis 2017, 265, 35-40. [CrossRef] [PubMed]

40. Yamashita, H.; Fujisawa, K.; Ito, E.; Idei, S.; Kawaguchi, N.; Kimoto, M.; Hiemori, M.; Tsuji, H. Improvement of obesity and glucose tolerance by acetate in Type 2 diabetic Otsuka Long-Evans Tokushima Fatty (OLETF) rats. Biosci. Biotechnol. Biochem. 2007, 71, 1236-1243. [CrossRef]

41. Reddy, J.K.; Rao, M.S. Lipid Metabolism and Liver Inflammation. II. Fatty liver disease and fatty acid oxidation. Am. J. Physiol. 2006, 290, 852-858. [CrossRef] [PubMed]

42. Cho, A.S.; Jeon, S.M.; Kim, M.J.; Yeo, J.; Seo, K.I.; Choi, M.S.; Lee, M.K. Chlorogenic acid exhibits anti-obesity property and improves lipid metabolism in high-fat diet-induced-obese mice. Food Chem. Toxicol. 2010, 48, 937-943. [CrossRef]

43. Bhutani, K.K.; Birari, R.B.; Kapat, K. Potential anti-obesity and lipid lowering natural products: A review. Nat. Prod. Commun. 2007, 2, 331-348.

44. Sunhee, C.; Miyeon, K.; Daieun, S. Spirulina prevents atherosclerosis by reducing hypercholesterolemia in rabbits fed a high-cholesterol diet. Sci. Vitaminol. 2010, 56, 34-40. [CrossRef]

45. Jin, D.; Xu, Y.; Mei, X.; Meng, Q.; Gao, Y.; Li, B. Antiobesity and lipid lowering effects of theaflavins on high-fat diet induced obese rats. J. Funct. Foods 2013, 5, 1142-1150. [CrossRef]

46. Torres-Duran, P.V.; Aldo, F.H.; Juarez-Oropeza, M.A. Antihyperlipemic and antihypertensive effects of Spirulina maximain an open sample of mexican population: A preliminary report. Lipids Health Dis. 2007, 6, 33. [CrossRef] [PubMed]

47. Singh, R.B.; Niaz, M.A.; Ghosh, S. Hypolipidemic and antioxidant effects of Commiphora mukul as an adjunct to dietary therapy in patients with hypercholesterolemia. Cardiovasc. Drugs Ther. 1994, 8, 659-664. [CrossRef]

48. Birari, R.; Javia, V.; Bhutani, K.K. Antiobesity and lipid lowering effects of Murraya koenigii (L.) Spreng leaves extracts and mahanimbine on high fat diet induced obese rats. Fitoterapia 2010, 81, 1129-1133. [CrossRef]

49. Chandrasekaran, C.V.; Vijayalakshmim, M.A.; Prakash, K. Review Article: Herbal Approach for Obesity Management. Am. J. Plant Sci. 2012, 3, 1003-1014. [CrossRef]

50. Kim, K.J.; Lee, M.S.; Jo, K.; Hwang, J.K. Piperidine alkaloids from Piper retrofractum Vahl. protect against high-fat diet-induced obesity by regulating lipid metabolism and activating AMP-activated protein kinase. Biochem. Biophys. Res. Commun. 2011, 411, 219-225. [CrossRef]

51. Sekiya, M.; Yahagi, N.; Matsuzaka, T.; Najima, Y.; Nakakuki, M.; Nagai, R.; Ishibashi, S.; Osuga, J.; Yamada, N.; Shimano, H. Polyunsaturated fatty acids ameliorate hepatic steatosis in obese mice by SREBP-1 suppression. Hepatology 2003, 38, 1529-1539. [CrossRef] [PubMed]

52. Shimano, H.; Horton, J.D.; Shimomura, I.; EHammer, R.; Brown, M.S.; Goldstein, J.L. Isoform 1c of sterol regulatory element binding protein is less active than isoform 1a in livers of transgenic mice and in cultured cells. J. Clin. Investig. 1997, 99, 846-854. [CrossRef] [PubMed]

53. Yang, Z.X.; Shen, W.; Sun, H. Effects of nuclear receptor FXR on the regulation of liver lipid metabolism in patients with non-alcoholic fatty liver disease. Hepatol. Int. 2010, 4, 741-748. [CrossRef] [PubMed] 
54. Takahashi, N.; Senda, M.; Lin, S.; Goto, T.; Yano, M.; Sasaki, T.; Murakami, S.; Kawada, T. Auraptene regulates gene expression involved in lipid metabolism through PPAR $\alpha$ activation in diabetic obese mice. Mol. Nutr. Food Res. 2011, 55, 1791-1797. [CrossRef] [PubMed]

55. Nagasawa, T.; Inada, Y.; Nakano, S.; Tamura, T.; Takahashi, T.; Maruyama, K.; Yamazaki, Y.; Kuroda, J.; Shibata, N. Effects of bezafibrate, PPAR pan-agonist, and GW501516, PPAR $\delta$ agonist, on development of steatohepatitis in mice fed a methionine- and choline-deficient diet. Eur. J. Pharmacol. 2006, 536, 182-191. [CrossRef] [PubMed]

56. EAkiyama, T.; Sakai, S.; Lambert, G. Conditional disruption of the peroxisome proliferator-activated receptor gamma gene in mice results in lowered expression of ABCA1, ABCG1, and apoE in macrophages and reduced cholesterol efflux. Mol. Cell. Biol. 2002, 22, 2607-2619. [CrossRef]

57. Foretz, M.; Viollet, B. Regulation of hepatic metabolism by AMPK. J. Hepatol. 2011, 54, 827-829. [CrossRef] [PubMed]

58. Kim, J.B.; Spiegelman, B.M. ADD1/SREBP1 promotes adipocyte differentiation and gene expression linked to fatty acid metabolism. Genes Dev. 1996, 10, 1096-1107. [CrossRef] [PubMed]

59. Kim, J.B.; Wright, H.M.; Wright, M.; Spiegelman, B.M. ADD1/SREBP1 activates PPAR $\gamma$ through the production of endogenous ligand. Proc. Natl. Acad. Sci. USA 1998, 95, 4333-4337. [CrossRef]

60. Berger, J.P. Role of PPARgamma, transcriptional cofactors, and adiponectin in the regulation of nutrient metabolism, adipogenesis and insulin action: View from the chair. Int. J. Obes. 2005, 29, S3. [CrossRef]

61. Berger, J.; Moller, D.E. The mechanism of action of PPARs. Ann. Rev. Med. 2002, 53, 409-444. [CrossRef] [PubMed]

62. Lei, F.; Zhang, X.N.; Zhang, W.; Wang, D.; Xie, W.; Su, H.; Du, L.J. Evidence of anti-obesity effects of the pomegranate leaf extract in high-fat diet induced obese mice. Int. J. Obes. 2007, 31, 1023. [CrossRef] [PubMed]

63. Herbert, T.; Moschen, A.R.; Kaneider, N.C. Pathways of liver injury in alcoholic liver disease. J. Hepatol. 2011, 55, 1159-1161. [CrossRef]

64. Dolan, K.T.; Chang, E.B. Diet, gut microbes, and the pathogenesis of inflammatory bowel diseases. Mol. Nutr. Food Res. 2016, 61, 1-38. [CrossRef]

65. Kimura, R.; Takahashi, N.; Murota, K.; Yamada, Y.; Niiya, S.; Kanzaki, N.; Murakami, Y.; Moriyama, T.; Goto, T.; Kawada, T. Activation of peroxisome proliferator-activated receptor- $\alpha$ (PPAR $\alpha$ ) suppresses postprandial lipidemia through fatty acid oxidation in enterocytes. Biochem. Biophys. Res. Commun. 2011, 410, 1-6. [CrossRef] [PubMed]

66. Neyrinck, A.M.; Taminiau, B.; Walgrave, H.; Daube, G.; Cani, P.D.; Bindels, L.B.; Delzenne, N.M. Spirulina Protects against Hepatic Inflammation in Aging: An Effect Related to the Modulation of the Gut Microbiota? Nutrients 2017, 9, 633-642. [CrossRef]

67. Fu, J.; Bonder, M.J.; Cenit, M.C.; Tigchelaar, E.F.; Maatman, A.; Dekens, J.A.M.; Brandsma, E.; Marczynska, J.; Imhann, F.; Weersma, R.K.; et al. The Gut Microbiome Contributes to a Substantial Proportion of the Variation in Blood Lipids. Circ. Res. 2015, 117, 817-824. [CrossRef]

68. Ubeda, C. Intestinal microbiota containing Barnesiella species cures vancomycin-resistant Enterococcus faecium colonization. Infect. Immun. 2013, 81, 965-973. [CrossRef]

69. Shang, Q.; Song, G.; Zhang, M.; Zhang, M.F.; Shi, J.; Xu, C.; Hao, J.; Li, G.; Yu, G. Dietary fucoidan improves metabolic syndrome in association with increased Akkermansia, population in the gut microbiota of high-fat diet-fed mice. J. Funct. Foods 2017, 28, 138-146. [CrossRef]

70. Brown, A.J.; Goldsworthy, S.M.; Barnes, A.A.; Eilert, M.M.; Tcheang, L.; Daniels, D.; Muir, A.I.; Wigglesworth, M.J.; Kinghorn, I.; Fraser, N.J.; et al. The Orphan G Protein-coupled Receptors GPR41 and GPR43 Are Activated by Propionate and Other Short Chain Carboxylic Acids. J. Biol. Chem. 2003, 278, 11312-11319. [CrossRef]

71. Henaomejia, J.; Elinav, E.; Jin, C.; Hao, L.; Mehal, W.Z.; Strowig, T.; Thaiss, C.A.; Kau, A.L.; Eisenbarth, S.C.; Jurczak, M.J.; et al. Inflammasome-mediated dysbiosis regulates progression of NAFLD and obesity. Nature 2012, 482, 179-185. [CrossRef] [PubMed]

72. Ley, R.E.; Bäckhed, F.; Turnbaugh, P.; Lozupone, C.A.; Knight, R.D.; Gordon, J.I. Obesity alters gut microbial ecology. Proc. Natl. Acad. Sci. USA 2005, 102, 11070-11075. [CrossRef] [PubMed] 
73. Guo, W.L.; Pan, Y.Y.; Li, L.; Li, T.T.; Lv, X.C. Ethanol extract of Ganoderma lucidum ameliorates lipid metabolic disorders and modulates the gut microbiota composition in high-fat diet fed rats. Food Funct. 2018, 1-9. [CrossRef] [PubMed]

74. Zhao, L.N.; Wang, S.Y.; Huang, S.L.; Huang, Y.F. Optimization of Chelation of Whey Protein Hydrolysate with Calcium Using Response Surface Method. Adv. Mater. Res. 2013, 781-784, 1856-1860. [CrossRef]

75. Luo, Y.C.; Gang, C.; Bo, L.; Guo, Y.; Yetukuri, L.; VIslam, S.; Felin, J.; Perkins, R.; Borén, J.; Oresic, M.; et al. Evaluation of antioxidative and hypolipidemic properties of a novel functional diet formulation of Auricularia auricula and Hawthorn. Innov. Food Sci. Emerg. 2009, 10, 215-221. [CrossRef]

76. Friedewald, W.T.; Levy, R.I. Estimation of the concentration of low-density lipoprotein cholesterol in plasma, without use of the preparative ultracentrifuge. Clin. Chem. 1972, 18, 499-505. [PubMed]

77. Cheng, H.; Xu, N.; Zhao, W.; Su, J.; Lian, M.; Xie, Z.; Wu, X.; Li, Q. (-)-Epicatechin regulates blood lipids and attenuates hepatic steatosis in rats fed high-fat diett. Mol. Nutr. Food Res. 2017, 61, 1700303. [CrossRef]

78. Mashmoul, M.; Azlan, A.; Mohtarrudin, N. Protective effects of saffron extract and crocin supplementation on fatty liver tissue of high-fat diet-induced obese rats. BMC Complem. Altern. M. 2016, 16, 401-405. [CrossRef]

79. Hernándezrodas, M.C.; Valenzuela, R.; Echeverría, F.; Rincón-Cervera, M.Á.; Espinosa, A.; Illesca, P.; Muñoz, P.; Corbari, A.; Romero, N.; Gonzalez-Mañan, D.; et al. Supplementation with Docosahexaenoic Acid and Extra Virgin Olive Oil Prevents Liver Steatosis Induced by a High-Fat Diet in Mice through PPAR- $\alpha$ and Nrf2 Upregulation with Concomitant SREBP-1c and NF-kB Downregulation. Mol. Nutr. Food Res. 2017, 61, 456-469. [CrossRef]

80. Li, K.; Zhuo, C.; Teng, C.; Yu, S.; Wang, X.; Hu, Y.; Ren, G.; Yu, M.; Qu, J. Effects of Ganoderma lucidum, polysaccharides on chronic pancreatitis and intestinal microbiota in mice. Int. J. Biol. Macromol. 2016, 93, 904-912. [CrossRef]

81. Henschel, A.; Anwar, M.Z.; Manohar, V. Comprehensive Meta-analysis of Ontology Annotated 16S rRNA Profiles Identifies Beta Diversity Clusters of Environmental Bacterial Communities. PLoS Comput. Biol. 2015, 11, e1004468. [CrossRef] [PubMed] 